\title{
Influence of Pt paste and the firing temperature of screen-printed electrodes on the NO detection by pulsed polarization
}

\author{
Nils Donker ${ }^{1}$, Anastasiya Ruchets ${ }^{2}$, Daniela Schönauer-Kamin ${ }^{1}$, Jens Zosel ${ }^{2}$, Ulrich Guth ${ }^{3}$, and \\ Ralf Moos ${ }^{1}$ \\ ${ }^{1}$ Department of Functional Materials, University of Bayreuth, 95440 Bayreuth, Germany \\ ${ }^{2}$ Kurt-Schwabe-Institut für Mess- und Sensortechnik e.V. Meinsberg, 04736 Waldheim, Germany \\ ${ }^{3}$ Faculty of Chemistry and Food Chemistry, Dresden University of Technology, 01069 Dresden, Germany
}

Correspondence: Ralf Moos (funktionsmaterialien@uni-bayreuth.de)

Received: 20 April 2020 - Revised: 4 July 2020 - Accepted: 21 July 2020 - Published: 17 September 2020

\begin{abstract}
Symmetrical Pt|YSZ|Pt sensors were produced by screen printing with frit-containing and fritless Pt pastes and fired at 950,1100 , and $1300^{\circ} \mathrm{C}$. Subsequently, the sensors were operated by pulsed polarization, and the NO sensitivity was investigated. The sensitivity of the sensors with fritless pastes was found to be significantly higher. The influence of the firing temperature was low in contrast to the influence of the paste. The low NO sensitivity of the frit-containing electrodes was attributed to a blocking effect that probably occurs at the triple-phase boundaries. Therefore, the oxygen transport through the sensor is inhibited, which, however, seems to be necessary for the sensor effect.
\end{abstract}

\section{Motivation}

Most electrochemical sensors for the detection of nitrogen oxides $\left(\mathrm{NO}_{x}\right.$; i.e., $\mathrm{NO}$ and $\left.\mathrm{NO}_{2}\right)$ are based on stationary principles. Examples are amperometric NO sensors or potentiometric mixed potential sensors (Zhuiykov and Miura, 2007; Liu et al., 2017; Miura et al., 1998; Ritter et al., 2019; Park et al., 2009; Liang et al., 2011). What these principles have in common is that the sensors provide a time-invariant measurement signal in the form of a current or a voltage at a constant analyte gas concentration. Dynamic methods such as cyclic voltammetry (Ruchets et al., 2019), thermocyclic operation (Zhang et al., 2015), or the pulsed polarization used here (Donker et al., 2019), on the contrary, use the dynamic response to an external excitation as the sensor signal. This promises to provide additional information and thus improves, in particular, the selectivity of the sensors. Electrodes, especially, might have a great influence on the polarization behavior, depending on morphology and impurities. These effects will be investigated here.

\section{Pulsed polarization method}

Pulsed polarization is a novel measuring method for detecting nitrogen oxides. It is based on the well-known Pt|YSZ|Pt (YSZ - yttria stabilized zirconia) system as the sensor setup. By cyclically applying a polarization voltage $U_{\text {pol }}$, the sensor is polarized for a defined period of time $\left(t_{\text {pol }}\right)$; see Fig. 1a. The sensor is then disconnected from the voltage source. The self-discharge, represented by the open circuit voltage $(\mathrm{OCV})$ of the sensor, is measured for a defined period of time $\left(t_{\text {discharge }}\right)$. After this discharge, the sensor is polarized again, but with a negative polarity, and then discharged again. This cycle that alternates the charging and discharging of the sensor is continued. It has been shown that the self-discharge of the sensor is significantly and selectively accelerated in the presence of nitrogen oxides (Fischer et al., 2010). This accelerated self-discharge can be used for nitrogen oxide detection by evaluating the voltages at a fixed time of the self-discharge, for example, $4 \mathrm{~s}$ after positive polarization $\left(U_{4 \mathrm{~s} \_p o s}\right)$. Due to the faster discharge, these voltage values are lower in the presence of NO than without NO. In addition to the good selectivity, this method has the advantage that no 
reference atmosphere is needed (Fischer et al., 2014). However, the processes leading to the sensor signal have not yet been fully understood. An examination of different electrode compositions and the influence of firing temperatures could provide additional information about the underlying mechanisms.

\section{Experimental procedure}

To investigate the influence of the electrode morphology on the sensor behavior, the electrodes $(A=3.5 \mathrm{~mm} \times 3.5 \mathrm{~mm})$ were screen printed with two different Pt pastes (fritcontaining and fritless paste) on both sides of a $300 \mu \mathrm{m}$ thick 8YSZ substrate (Kerafol $\mathrm{GmbH})$ and then fired at 950, 1100, or $1300^{\circ} \mathrm{C}$, respectively. The sensors produced in this way were contacted with a $0.1 \mathrm{~mm}$ thick Pt-wire and then operated in a gas-purgeable furnace at $400^{\circ} \mathrm{C}$. This temperature has been shown as being the optimum working temperature for Pt|YSZ|Pt-NO sensors that are operated by the pulsed polarization method (Fischer et al., 2015). As base gas, $10 \%$ $\mathrm{O}_{2}$ in $\mathrm{N}_{2}$ with approximately $2 \% \mathrm{H}_{2} \mathrm{O}$ was used. In addition, $5,10,25$, and 50 parts per million (ppm) NO were stepwise added to the base gas for $15 \mathrm{~min}$ each. The parameters selected for the pulsed polarization measurements were polarization voltage $U_{\mathrm{pol}}=1 \mathrm{~V}$, polarization duration $t_{\mathrm{pol}}=1 \mathrm{~s}$, and discharge duration $t_{\text {discharge }}=10 \mathrm{~s}$.

Cross sections of sensor samples were studied under the scanning electron microscope (SEM) and analyzed by energy dispersive X-ray spectroscopy (EDX).

In order to investigate the polarization properties of the sensors, stationary $U-I$ characteristics were recorded. The applied voltage was varied in $10 \mathrm{mV}$ steps as indicated in Fig. $1 \mathrm{~b}$ from 0 to $1 \mathrm{~V}$ and to $-1 \mathrm{~V}$ and then back to $0 \mathrm{~V}$. Each step was held until a constant current value was reached but at least $30 \mathrm{~s}$ and not more than $60 \mathrm{~s}$. These measurements were conducted in base gas and in base gas with additional $50 \mathrm{ppm}$ NO.

\section{Results and discussion}

\subsection{SEM}

Cross section SEM images of Pt|YSZ substrates (Fig. 2) show for both pastes a decreasing porosity of the Ptelectrodes with increasing sintering temperature (Fig. 2a-c and $d-f)$. In case of electrodes printed with frit-containing paste (Fig. 2d-f), this frit is visible in dark gray. EDX analyses (not shown here) show that this frit mainly consists of a silica phase that is uniformly distributed in the electrode fired at $950^{\circ} \mathrm{C}$ (Fig. 2d) and fills some pores, while other pores are still free (black area). At higher firing temperatures (Fig. 2e-f), however, a continuous interface layer consisting of frit is formed between the Pt electrode and the YSZ substrate, which should ensure good adhesion. Nevertheless, this layer probably can also reduce the length of the triple- phase boundary (tpb) gas $\mid$ YSZ $\mid$ electrode. Since the oxygen exchange takes place at the tpb, a reduction of its length is expected to lead to a reduced current density (see $U-I$ characteristics).

\subsection{Pulsed polarization measurements}

The sensors produced with frit-containing and fritless paste were polarized and depolarized using the pulsed polarization technique. Sensor signals were generated from the discharge curves by, for example, evaluating the voltage $4 \mathrm{~s}$ after each positive polarization $U_{4 \text { s_pos }}$ (see Fig. 1). Due to the cycle period of $22 \mathrm{~s}\left(2 \cdot t_{\text {pol }}+2 \cdot t_{\text {discharge }}\right)$, a new value of $U_{4 \mathrm{~s} \_ \text {pos }}$ was generated every $22 \mathrm{~s}$.

The resulting signals for the sensors made of fritless paste are shown in Fig. 3a. The straight course of these signals shows the high stability of the cycles, comparable to stable cycles in cyclic voltammetry (CV) measurements. Only a slight drift in the presence of base gas can be detected. If NO is added to the base gas, the self-discharge of the sensor is strongly accelerated. This acceleration in turn causes the voltages to be lower than they would be without NO, which is clearly visible in the sensor signals.

Among the sensors manufactured with fritless paste, the sensors fired at $1100^{\circ} \mathrm{C}$ provide the greatest voltage difference when NO is added. However, a clear NO-dependent accelerated discharge can be seen at sensors fired at all temperatures. In the general discharge behavior, the sensors with a fritless paste show a clear dependency on the firing temperature. Thus, sensors fired at higher temperatures discharge much more slowly than sensors fired at lower temperatures. This is reflected in Fig. 3a in the higher voltages of $U_{4 \text { s_pos }}$ but is evident throughout the entire discharge. The difference between 1300 and $1100^{\circ} \mathrm{C}$ is particularly clear here.

The signals of the sensors produced with frit-containing paste are shown in Fig. 3b. Here, the sensors fired at $950^{\circ} \mathrm{C}$ show the highest NO sensitivity. At higher firing temperatures of the sensor electrodes, almost no discharge accelerated by NO is visible. In contrast to the sensors made of fritless pastes, no clear correlation between firing temperature and discharge rate can be seen.

If one considers the voltage difference $\Delta U_{4 \mathrm{~s} \text { _pos }}$ between the base gas signal before the sensor was first exposed to $\mathrm{NO}$ and the respective voltages with NO, the sensors show a logarithmic dependence between voltage difference and NO concentration. The sensitivity is - especially with regard to the fit accuracy - almost similar for all sensors with a fritless paste. It reaches values between 93 and $107 \mathrm{mV}$ per decade $c_{\mathrm{NO}}$; see Fig. 4 . The sensor fired at $1100^{\circ} \mathrm{C}$ shows the highest absolute voltage difference. For sensors containing frit, the sensitivity is highest for the sensor fired at $950{ }^{\circ} \mathrm{C}$ with $25 \mathrm{mV}$ per decade $c_{\mathrm{NO}}$. At higher firing temperatures, the NO sensitivity is lower than the drift with the selected parameters. 

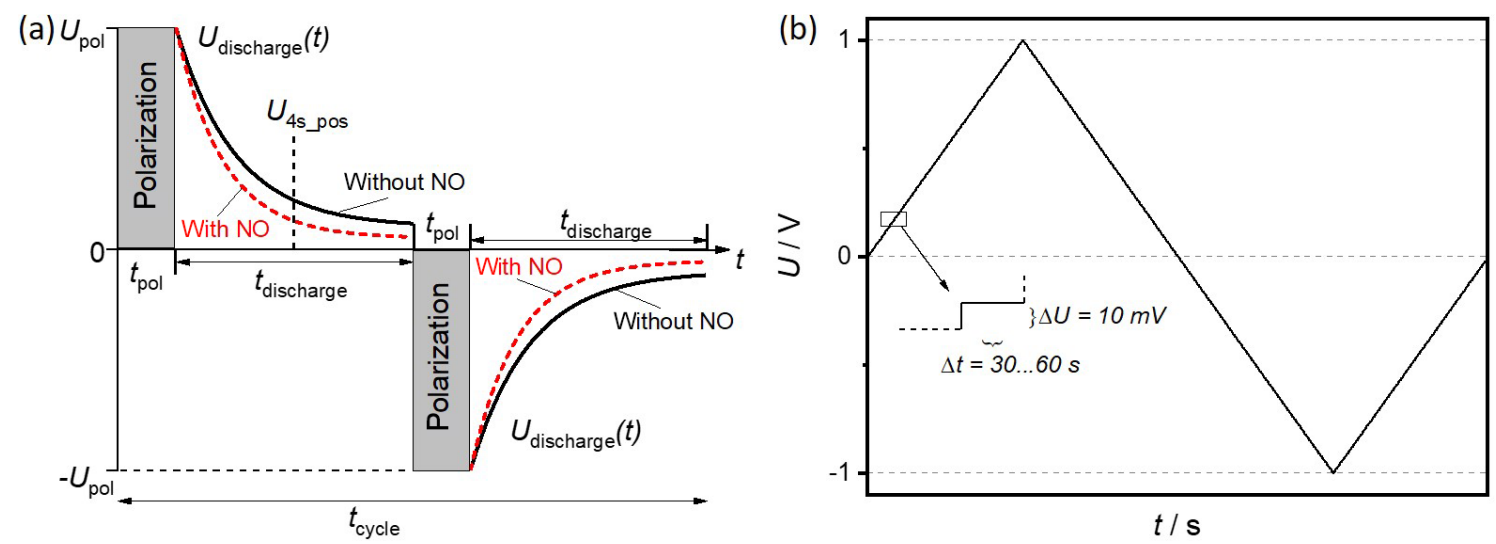

Figure 1. Scheme of a pulsed polarization cycle (a), and the $U-I$ measurements (b).
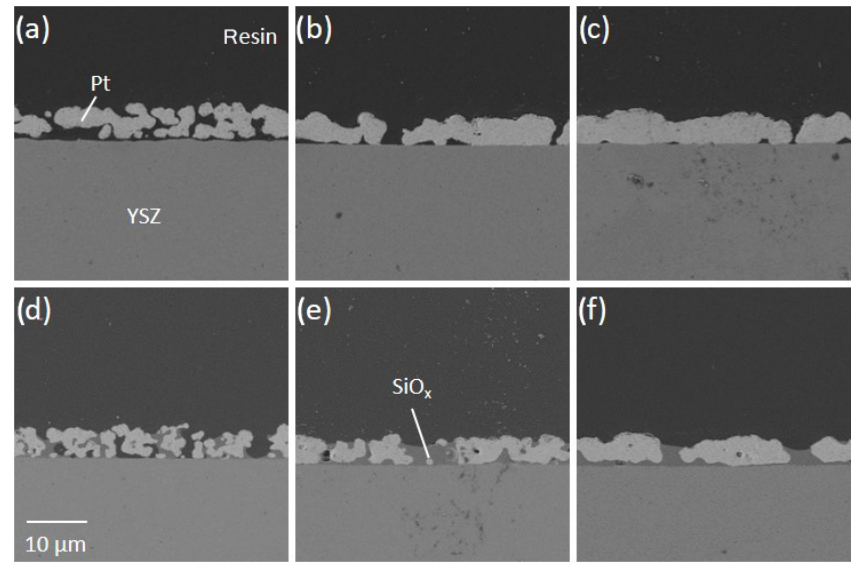

Figure 2. SEM cross section images of the electrodes without $(\mathbf{a}-\mathbf{c})$ and with glass frit $(\mathbf{d}-\mathbf{f})$, fired at $950^{\circ} \mathrm{C}(\mathbf{a}, \mathbf{d}), 1100^{\circ} \mathrm{C}(\mathbf{b}, \mathbf{e})$, and $1300^{\circ} \mathrm{C}(\mathbf{c}, \mathbf{f})$.

\subsection{U-/ characteristics}

In order to characterize the electrodes during polarization, $U-I$ curves were recorded in "steady-state" measurements for both sensors with different pastes. Results in the form of Tafel plots are seen in Fig 5. In this context, the calculated current densities $(|j|)$ of electrodes without glass frit $(\mathrm{a}-\mathrm{c})$ are clearly higher than those obtained from electrodes with frit (d-f). Thus, the current density of the electrodes with frit is about 2-3 times smaller than the current density of the electrodes without frit.

Among the fritless electrodes (Fig. 5a-c), the sensor fired at $950^{\circ} \mathrm{C}$ shows the lowest current densities when polarized. The current densities of sensors fired at higher temperatures are almost 10 times higher. However, there are only very small differences in the current density between sensors fired at 1100 and $1300^{\circ} \mathrm{C}$. For all samples, the currents are significantly higher during NO exposure. Furthermore, the sensors show a slight hysteresis due to the previous polarization. The presence of $\mathrm{NO}$ reduces the hysteresis for the electrodes fired at 950 and $1100^{\circ} \mathrm{C}$. This means that the hysteresis with NO being present in the gas is almost nonexistent for these sensors.

As written above, the current densities of frit-containing electrodes are significantly lower than those of fritless electrodes. The maximum current densities of these sensors decrease with increasing firing temperature. The hysteresis is even more pronounced with these sensors. Here, too, the addition of NO leads to higher currents and to a smaller hysteresis.

\section{Discussion}

\subsection{Processes during polarization}

For a detailed discussion of the presented results, it must first be clarified what happens during the polarization of the sensors. Without applying a polarization voltage, oxygen and oxide ions in the electrolyte on both electrodes are in equilibrium Eq. (R1).

$\mathrm{O}_{2}+4 e^{-} \rightleftarrows 2 \mathrm{O}^{2-}$.

For similar electrodes on both sides, and since both electrodes are exposed to the same gas atmosphere, a voltage difference of $0 \mathrm{~V}$ between both electrodes is the consequence, according to the Nernst equation Eq. (1).

$U=\frac{R T}{z F} \ln \left(\frac{p \mathrm{O}_{2}^{\mathrm{I}}}{p \mathrm{O}_{2}^{\mathrm{II}}}\right)$.

Here, $U$ is the sensor voltage, $R$ is the universal gas constant, $T$ is the absolute temperature, $z$ is the number of electrons transferred, and $F$ is the Faraday constant. The terms $p \mathrm{O}_{2}^{\mathrm{I}}$ and $p \mathrm{O}_{2}^{\mathrm{II}}$ represent the oxygen partial pressure at the electrodes I and II, respectively.

By applying the polarization voltage of $1 \mathrm{~V}$, this equilibrium Eq. (R1) is shifted at both electrodes. Even if the ap- 

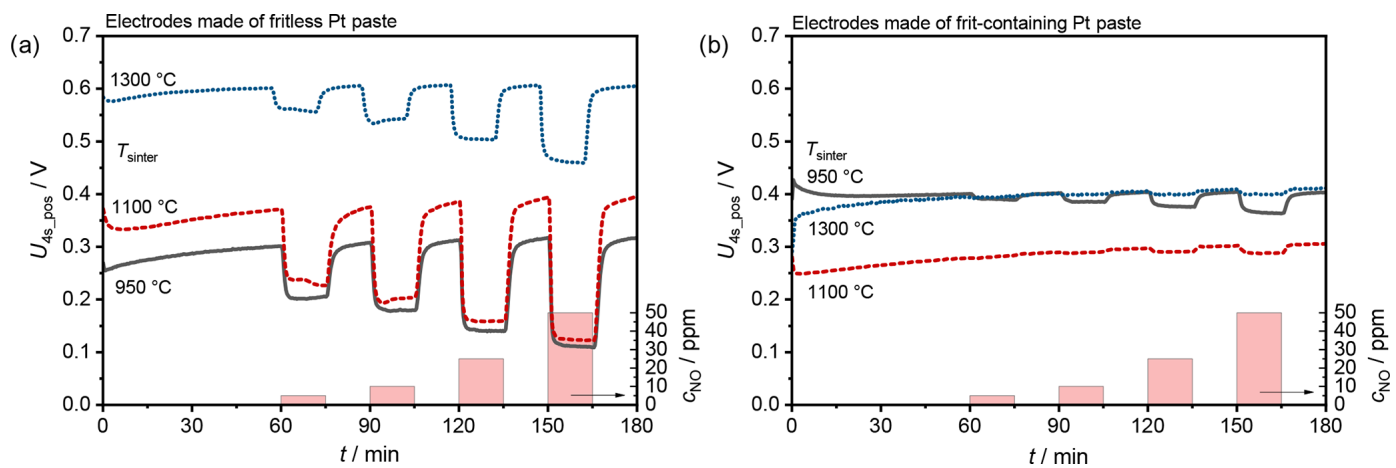

Figure 3. Sensor signal of the sensors (a) with fritless and (b) with frit-containing Pt paste.

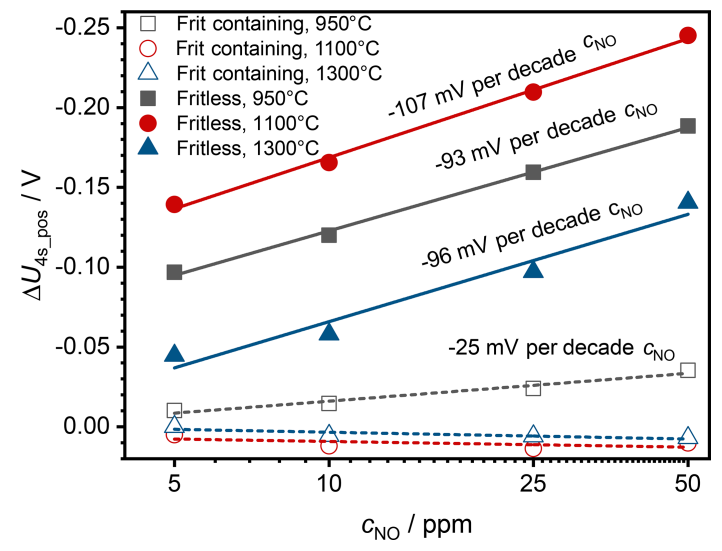

Figure 4. Sensor characteristics towards NO for different pastes.

plied voltage does not lead in full to a partial pressure difference according to Eq. (1), (kinetic and ohmic losses may also have to be taken into account), a shift in the partial pressures can still be assumed. An indicator for that is the high voltage even $4 \mathrm{~s}$ after polarization (Fig. 3), which otherwise would have to be much lower. If the oxygen exchange is also considered in more detail, the adsorption of oxygen from the gas phase occurs at the cathode (Eq. R2).

$\mathrm{O}_{2(\text { gas })} \rightarrow \mathrm{O}_{2(\mathrm{Pt})}$.

This oxygen dissociates as illustrated in Fig. 6a (Eq. R3).

$\frac{1}{2} \mathrm{O}_{2(\mathrm{Pt})} \rightarrow \mathrm{O}_{(\mathrm{Pt})}$.

It then diffuses to the triple-phase boundary (tpb), as represented by Eq. (R4; cf. Fig. 6b).

$\mathrm{O}_{(\mathrm{Pt})} \rightarrow \mathrm{O}_{(\mathrm{tpb})}$

Then oxygen is incorporated at the triple-phase boundary into YSZ, including a charge transfer reaction (Eq. R5; cf. Fig. 6c).

$\mathrm{O}_{(\mathrm{tpb})}+2 e^{-} \rightarrow \mathrm{O}_{(\mathrm{YSZ})}^{2-}$.
At the anode, all these reactions occur in the opposite direction.

Although no 3D reconstruction of the three-phase boundaries and the electrodes was performed as in Flegel et al. (2017), it can be assumed that, for sensors made of fritcontaining paste, a large part of the three-phase boundaries is blocked by the frit (see Fig. 2d-f). According to the literature (Mogensen, 2002; Hauch et al., 2007; Hertz et al., 2009; Mutoro et al., 2009, 2010), this leads to a lower exchange current density. It makes other oxygen exchange mechanisms conceivable as well. On the one hand, part of the frit and other impurities may be reduced or oxidized (Mutoro et al., 2009; Fig. 6d). On the other hand, in the presence of anodic polarization, blistering might be possible under the dense Si layer; Eq. (R6; Fig. 6e).

$\mathrm{O}_{(\mathrm{YSZ})}^{2-} \rightarrow \mathrm{O}_{(\mathrm{tpb})}+2 e^{-}$.

This blistering has already been observed with dense platinum electrodes (Pöpke et al., 2011; Mutoro et al., 2008).

The amount of oxygen transported by the polarization current can be determined using Faraday's law Eq. (2) as follows:

$m=\frac{M \cdot Q}{z \cdot F}$,

with $m$ being the mass of transported species, $Q$ the amount of charge transported during polarization, $z$ the charge number of oxygen ions, and $F$ the Faraday constant. $Q$ was determined by integrating the polarization currents over the duration of the positive polarizations for each cycle.

The calculated mass of oxygen $m_{\mathrm{O}}$ transported during the positive polarization cycles is displayed in Fig. 7 for all electrodes. In the case of the frit-containing electrodes, only a very small amount of oxygen is transported compared to the fritless electrodes. This correlates well with the significantly lower currents during the steady-state polarization measurements (see Fig. 4).

Furthermore, the sensor with the fritless electrodes shows a slight NO dependence on oxygen transported during the polarization. One reason is probably the additional reduction 

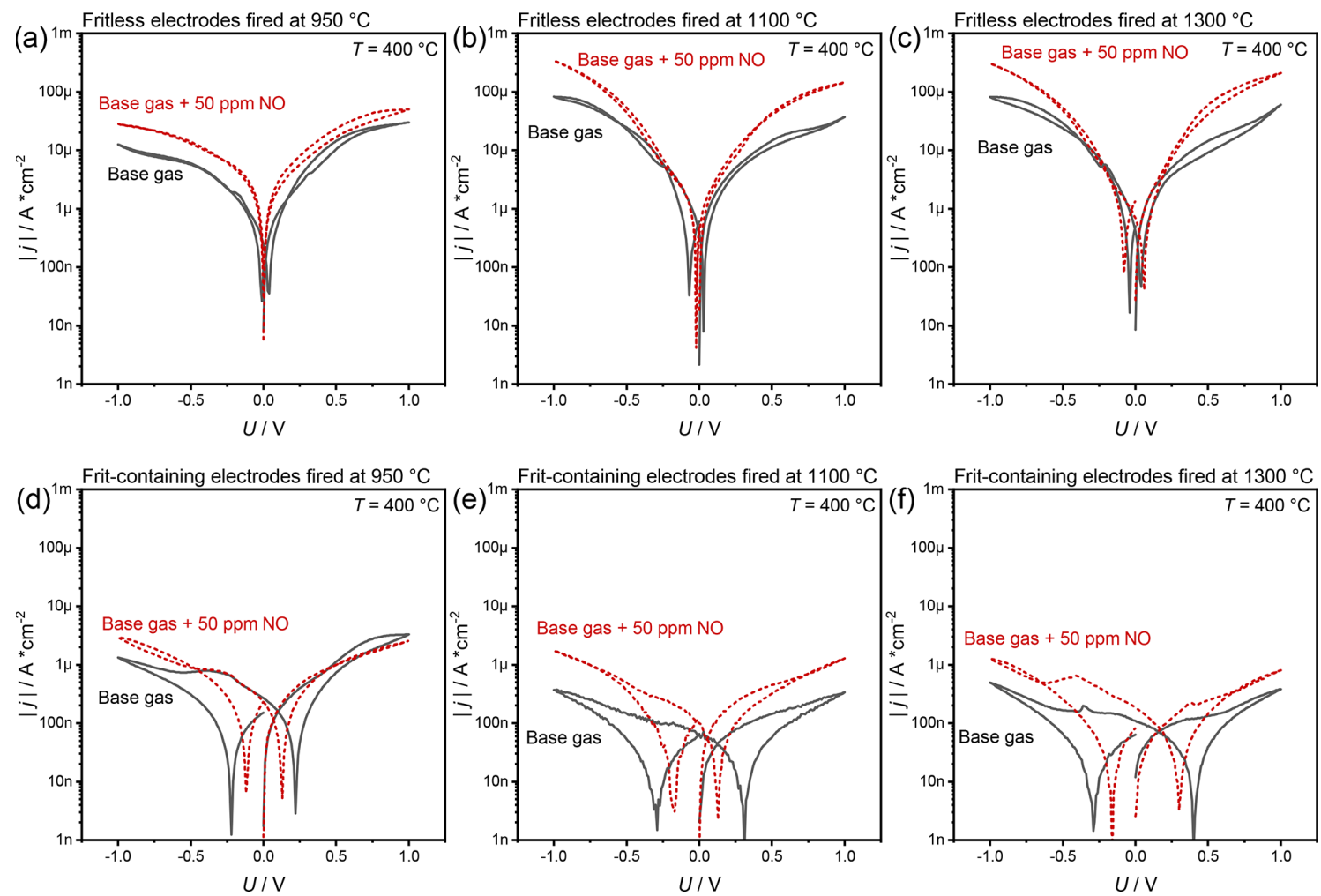

Figure 5. Polarization curves of sensors without (a-c) and with glass frit (d-f), fired at $950{ }^{\circ} \mathrm{C}(\mathbf{a}, \mathbf{d}), 1100^{\circ} \mathrm{C}(\mathbf{b}, \mathbf{e})$, and $1300{ }^{\circ} \mathrm{C}(\mathbf{c}, \mathbf{f})$.

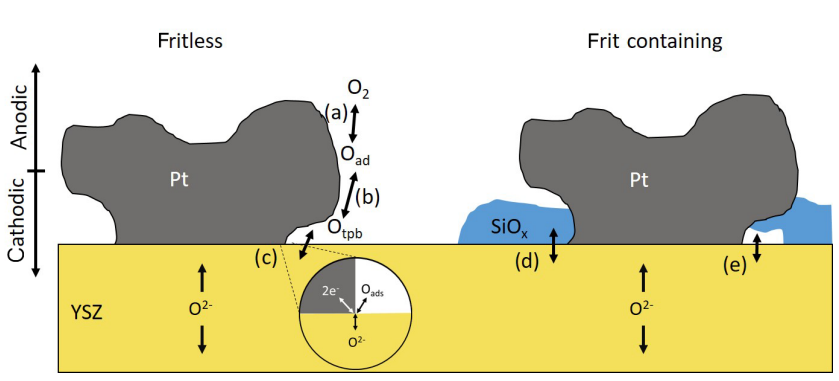

Figure 6. Possible processes indicated by (a)-(e) at the Pt|YSZ interface for fritless and frit-containing electrodes.

of $\mathrm{NO}$ and thus a larger oxygen transport. A second reason could also be the reduction of $\mathrm{NO}_{2} . \mathrm{NO}_{2}$ is probably also present at the electrodes' tpb since, at a sensor temperature of $400{ }^{\circ} \mathrm{C}$ in conjunction with the high catalytic activity of the platinum electrodes, one may expect that the thermodynamic equilibrium $\mathrm{NO} / \mathrm{NO}_{2}$ (approx. 50/50) can be established (Bhatia et al., 2009).

This NO dependency on the transported oxygen is not visible for sensors with frit-containing electrodes. This contradicts the steady-state polarization measurements. They showed higher currents with NO, which should also lead to a higher oxygen transport during polarization.

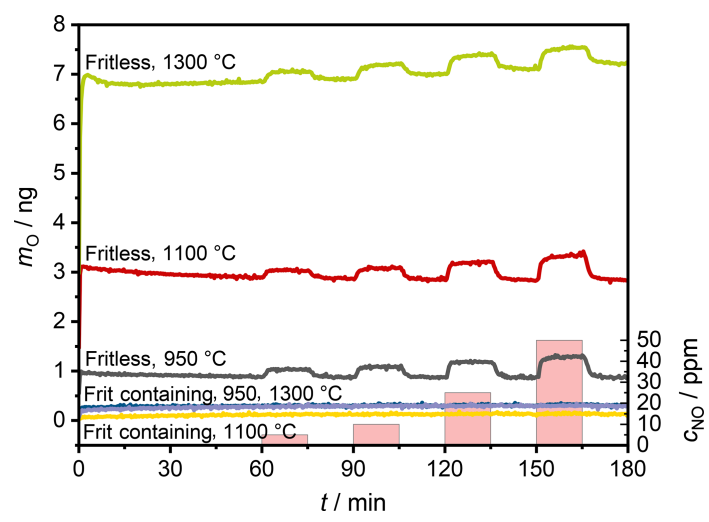

Figure 7. Pumped oxygen $m_{\mathrm{O}}$ pumped during positive polarization pulses of $1 \mathrm{~V}$.

These current differences are probably too small to be visible during the short polarization times (approx. $1 \mu \mathrm{A}$ or $1 \mu \mathrm{Cs}^{-1}$ ) compared to the sensors with fritless electrodes (approx. $10 \mu \mathrm{C} \mathrm{s}^{-1}$ ). Furthermore, the long polarization time of the steady-state measurements differs significantly from the pulsed polarization measurements. Therefore, the different mechanisms may occur more strongly during long polarizations rather than during short polarizations. An example would be to crack the abovementioned bubbles under $\mathrm{SiO}_{x}$ during long polarizations, which would allow an exchange 
with the surrounding gas phase. This exchange would not occur with short polarizations and thus closed bubbles. Moreover, any reactions with the frit or impurities would also be completed, or at least slowed down considerably, at some point. This would lead to the fact that the oxygen exchange is more important again. This oxygen exchange is supported by NO.

\subsection{Processes during self-discharge}

After polarization, the sensor discharges and its behavior tends to thermodynamic equilibrium or to the steady state due to formation of a mixed potential, namely its nonequilibrated stable value. To achieve this, the oxygen gradient between the electrodes, which is forced by the applied polarization voltage, must be reduced. To achieve this, on the one hand oxygen must adsorb on the depleted cathode, and on the other hand oxygen must desorb on the oxygen-rich anode. Although the exact effect is yet under study, the added NO has two possible functions to accelerate this. On the one hand, $\mathrm{NO}$, just like $\mathrm{NO}_{2}$, can be reduced at the oxygendepleted electrode. Thus, it supplies additional oxygen to the cathode. Secondly, $\mathrm{NO}$ might be oxidized to $\mathrm{NO}_{2}$ at the oxygen-rich anode and thus help to decrease the oxygen concentration at this electrode. Both effects would lead to a faster reduction of the oxygen gradient and thus to a faster selfdischarge behavior.

However, this discharge, accelerated by NO, hardly occurs in sensors with electrodes that contain a frit (Fig. 2). A distinction must therefore be made between them and sensors with fritless electrodes. Compared to the influence of the frit, the firing temperature has only a very small influence on the NO sensitivity (see Fig. 3).

The polarization measurements show significantly higher current densities when the sensors are exposed to an NOcontaining base gas. This corresponds to a faster charge transfer that could explain the faster decay of the charge difference. However, this would apply to electrodes made from both pastes. The difference in the frit-containing electrodes probably lies in the combination of the small polarization currents, on the one hand, and in the hysteresis of the polarization measurements, on the other hand.

As shown in Fig. 7, the frit-containing sensors transport significantly less oxygen during polarization than the fritless sensors. With the latter, there seems to be a correlation between the previously transported charge and the speed of discharge. The more oxygen was previously pumped, the slower the sensor discharges.

A large amount of transported oxygen correlates with a small resistance between the electrodes when a constant voltage is applied. With a low resistance, however, a faster selfdischarge would also be expected. The measurements show that this is not the case. Rather, it seems to take longer for the larger amount of previously transported oxygen to return to equilibrium.
Based on these considerations, the sensors containing frit would have to discharge very quickly. Since the tpb sites are probably blocked by the frit, almost no oxygen is pumped through the sensor. The fact that they discharge only slowly is probably related to the high hysteresis of the polarization measurements. This high hysteresis, in combination with the slow measurements $\left(<0.3 \mathrm{mV} \mathrm{s}^{-1}\right)$, shows very high capacitances. Such pseudocapacitive behavior has been attributed in the literature to the formation of gas reservoirs (Bay and Jacobsen, 1997) and to charge storage in the form of chemical species (Jaccoud et al., 2007). Both could also occur with these sensors and would explain the slow discharge. In addition, both effects take place mainly at the Pt|YSZ interface without access to the surrounding gas atmosphere. Thus, bubbles would only form if the anodically generated oxygen cannot escape into the gas phase via a triple-phase contact. And the reactions with the frit also occur mainly without access to the gas phase. This is likely, since the geometric area without gas access is significantly larger than the area with gas access (Fig. 2). So both processes could lead to a slower discharge of the sensor, but both processes would also hardly be influenced by the presence of NO. This might be the case especially because the NO does not reach a large part of the relevant areas.

\section{Summary}

Symmetrical Pt|YSZ|Pt sensors were prepared with platinum electrodes made of two different pastes, and each one was fired at three different temperatures. Subsequently, the NO sensitivity of these sensors during cyclic discharge after pulsed polarization was investigated. It could be shown that the firing temperatures, and thus the porosity of the electrodes during pulsed polarization, have only a relatively small influence on the NO sensitivity. In contrast, the choice of the paste is much more critical. Sensors with a paste that contains a frit have a significantly lower sensitivity than sensors with electrodes without frit. This is probably due to a passivation layer between electrode and electrolyte caused by the frit. It probably hinders the transfer of charge at the triplephase boundary or blocks the gas transport in the porous layer. However, the charge transfer, especially the exchange of oxygen, seems to be a prerequisite for the sensor effect. In the frit-containing paste, pseudocapacitive effects seem to dominate the self-discharge of the sensor.

Author contributions. RM and JZ created the concept of the project, respecting ideas of UG, and are responsible for funding acquisition. Methodology was developed by ND and DSK in close discussion with RM and UG. ND constructed the setup, conducted the investigation process, and wrote the original draft. ND and AR developed the supporting algorithms and computer code for processing and analyzing the data. All authors contributed to the inter- 
pretation of the data and to the reviewing and editing of the final paper. RM supervised the work.

Data availability. All relevant data presented in the article are stored according to institutional requirements and, as such, are not available online. However, all data used in this paper can be made available upon request.

Competing interests. The authors declare that they have no conflict of interest.

Special issue statement. This article is part of the special issue "Dresden Sensor Symposium DSS 2019". It is a result of the "14. Dresdner Sensor-Symposium”, Dresden, Germany, 2-4 December 2019.

Acknowledgements. We would like to thank Judith Zander for performing the pulsed polarization measurements and Angelika Mergner and the Keylab Electron and Optical Microscopy of the Bavarian Polymer Institute (BPI) for the SEM images.

Financial support. This research has been supported by the German Research Foundation (DFG; grant nos. MO 1060/30-1 and ZO 139/3-1).

This open-access publication was funded by the University of Bayreuth.

Review statement. This paper was edited by Holger Fritze and reviewed by two anonymous referees.

\section{References}

Bay, L. and Jacobsen, T.: Dynamics of the YSZ-Pt interface, Solid State Ionics, 93, 201-206, https://doi.org/10.1016/S01672738(96)00526-7, 1997.

Bhatia, D., McCabe, R. W., Harold, M. P., and Balakotaiah, V.: Experimental and kinetic study of NO oxidation on model Pt catalysts, J. Catal., 266, 106-119, https://doi.org/10.1016/j.jcat.2009.05.020, 2009.

Donker, N., Ruchets, A., Schönauer-Kamin, D., Zosel, J., Guth, U., and Moos, R.: Influence of polarization time and polarization current of Pt|YSZ-based NO sensors utilizing the pulsed polarization when applying constant charge, Sensor. Actuat. B, 290, 28-33, https://doi.org/10.1016/j.snb.2019.03.060, 2019.

Fischer, S., Pohle, R., Farber, B., Proch, R., Kaniuk, J., Fleischer, M., and Moos, R.: Method for detection of $\mathrm{NO}_{x}$ in exhaust gases by pulsed discharge measurements using standard zirconia-based lambda sensors, Sensor. Actuat. B, 147, 780-785, https://doi.org/10.1016/j.snb.2010.03.092, 2010.
Fischer, S., Pohle, R., Magori, E., Fleischer, M., and Moos, R.: Detection of NO by pulsed polarization of Pt I YSZ, Solid State Ionics, 262, 288-291, https://doi.org/10.1016/j.ssi.2014.01.022, 2014.

Fischer, S., Schönauer-Kamin, D., Pohle, R., Fleischer, M., and Moos, R.: Influence of operation temperature variations on NO measurements in low concentrations when applying the pulsed polarization technique to thimble-type lambda probes, J. Sens. Sens. Syst., 4, 321-329, https://doi.org/10.5194/jsss-4-321-2015, 2015.

Flegel, E., Vonau, C., and Guth, U.: Characterization of Pt, $\mathrm{O}_{2} \mid$ YSZ electrodes for lambda probes and their ageing in humid atmosphere, Tech. Mess., 84, 635-643, https://doi.org/10.1515/teme2016-0079, 2017.

Hauch, A., Jensen, S. H., Bilde-Sörensen, J. B., and Mogensen, M.: Silica Segregation in the Ni/YSZ Electrode, Solid State Ionics, 154, A619, https://doi.org/10.1149/1.2733861, 2007.

Hertz, J. L., Rothschild, A., and Tuller, H. L.: Highly enhanced electrochemical performance of silicon-free platinumyttria stabilized zirconia interfaces, J. Electroceram., 22, 428435, https://doi.org/10.1007/s10832-008-9475-5, 2009.

Jaccoud, A., Falgairette, C., Fóti, G., and Comninellis, C.: Charge storage in the $\mathrm{O}_{2(g)}, \mathrm{Pt} / \mathrm{YSZ}$ system, Electrochim. Acta, 52, 7927-7935, https://doi.org/10.1016/j.electacta.2007.06.046, 2007.

Liang, X., Yang, S., Li, J., Zhang, H., Diao, Q., Zhao, W., and Lu, G.: Mixed-potential-type zirconia-based $\mathrm{NO}_{2}$ sensor with highperformance three-phase boundary, Sens. Actuators B, 158, 1-8, https://doi.org/10.1016/j.snb.2011.02.051, 2011.

Liu, T., Wang, X., Li, L., and Yu, J.: Review - Electrochemical NO${ }_{x}$ Gas Sensors Based on Stabilized Zirconia, J. Electrochem. Soc., 164, B610-B619, https://doi.org/10.1149/2.0501713jes, 2017.

Miura, N., Lu, G., and Yamazoe, N.: High-temperature potentiometric/amperometric $\mathrm{NO}_{x}$ sensors combining stabilized zirconia with mixed-metal oxide electrode, Sensor. Actuat. B, 52, 169 178, 1998.

Mogensen, M.: Progress in understanding SOFC electrodes, Solid State Ionics, 150, 123-129, https://doi.org/10.1016/S01672738(02)00269-2, 2002.

Mutoro, E., Baumann, N., and Janek, J.: Janus-Faced $\mathrm{SiO}_{2}$ Activation and Passivation in the Electrode System Platinum/YttriaStabilized Zirconia, J. Phys. Chem. Lett., 1, 2322-2326, https://doi.org/10.1021/jz1006884, 2010.

Mutoro, E., Luerssen, B., Günther, S., and Janek, J.: The electrode model system $\mathrm{Pt}\left(\mathrm{O}_{2}\right) \mid$ YSZ: Influence of impurities and electrode morphology on cyclic voltammograms, Solid State Ionics, 180, 1019-1033, https://doi.org/10.1016/j.ssi.2009.04.012, 2009.

Mutoro, E., Sebastian, G., Luerssen, B., Valov, I., and Janek, J.: Electrode activation and degradation: Morphology changes of platinum electrodes on YSZ during electrochemical polarisation, Solid State Ionics, 179, 1835-1848, https://doi.org/10.1016/j.ssi.2008.05.007, 2008.

Park, J., Yoon, B. Y., Park, C. O., Lee, W.-J., and Lee, C. B.: Sensing behavior and mechanism of mixed potential $\mathrm{NO}_{x}$ sensors using $\mathrm{NiO}, \mathrm{NiO}(+\mathrm{YSZ})$ and $\mathrm{CuO}$ oxide electrodes, Sensor. Actuat. B, 135, 516-523, https://doi.org/10.1016/j.snb.2008.10.006, 2009.

Pöpke, H., Mutoro, E., Luerssen, B., and Janek, J.: The potential of in situ-scanning electron microscopy Morphology changes of electrically polarized thin film 
$\mathrm{Pt}\left(\mathrm{O}_{2}\right) /$ YSZ model electrodes, Solid State Ionics, 189, 56-62, https://doi.org/10.1016/j.ssi.2011.02.021, 2011.

Ritter, T., Lattus, J., Hagen, G., and Moos, R.: On the influence of the $\mathrm{NO}_{x}$ equilibrium reaction on mixed potential sensor signals: A comparison between FE modelling and experimental data, Sensor. Actuat. B, 296, 126627, https://doi.org/10.1016/j.snb.2019.126627, 2019.

Ruchets, A., Donker, N., Schönauer-Kamin, D., Moos, R., Zosel, J., Guth, U., and Mertig, M.: Selectivity improvement towards hydrogen and oxygen of solid electrolyte sensors by dynamic electrochemical methods, Sensor. Actuat. B, 290, 53-58, https://doi.org/10.1016/j.snb.2019.03.063, 2019.
Zhang, X., Kohler, H., Schwotzer, M., and Guth, U.: Mixedpotential gas sensor with PtAu-8YSZ sensing electrode: Electric potential difference measurements at isothermal and thermo-cyclic operation, Sensor. Actuat. B, 217, 107-112, https://doi.org/10.1016/j.snb.2014.10.106, 2015.

Zhuiykov, S. and Miura, N.: Development of zirconia-based potentiometric $\mathrm{NO}_{x}$ sensors for automotive and energy industries in the early 21st century: What are the prospects for sensors?, Sensor. Actuat. B, 121, 639-651, https://doi.org/10.1016/j.snb.2006.03.044, 2007. 